\title{
Kinematic Characteristics of Male Runners With a History of Recurrent Calf Muscle Strain Injury
}

Christopher Bramah, PhD, MCSP ${ }^{1}$ a, Stephen J Preece, PhD ${ }^{1}$, Niamh Gill, PhD ${ }^{1}$, Lee Herrington, PhD, MCSP

${ }^{1}$ Health Sciences Research Centre, University of Salford

Keywords: running, movement system, kinematics, injury, gait, calf muscle

https://doi.org/10.26603/001c.22971

\section{International Journal of Sports Physical Therapy}

Vol. 16, Issue 3, 2021

\section{Background}

Calf muscle strain injuries are a common running injury affecting male runners and are known to have high reoccurrence rates. Currently, limited evidence exists investigating factors associated with this injury with no previous study investigating the running kinematics of male runners with a history of repeat calf muscle strain injuries.

\section{Purpose}

To investigate whether male runners with a history of repeat calf muscle strain injury demonstrate differences in stance phase running kinematics when compared to healthy controls.

\section{Study Design}

Case-control investigation

\section{Level of Evidence}

$3 b$

\section{Methods}

Stance phase kinematics were compared between 15 male runners with a history of calf muscle strain injury and 15 male control participants during treadmill running at $3.2 \mathrm{~m} / \mathrm{s}$. Independent t-tests were used to compare differences in stance phase kinematic parameters between groups and effect sizes were calculated using Cohen's $\mathrm{d}$.

\section{Results}

The group with a history of calf muscle strain injury demonstrated a significant $2.1^{\circ}$ and $3.1^{0}$ increase in contralateral pelvic drop and anterior pelvic tilt during mid stance. In addition, this group exhibited longer stance times and a more anterior tilted pelvis, flexed hip and a greater distance between the heel and centre of mass at initial contact. Large effect sizes, greater than 0.8 , were observed for all differences. No significant differences were observed for ankle and knee joint kinematics between the groups.

\section{Conclusion}

This is the first study to identify kinematic characteristics associated with recurrent calf muscle strain injury. While it is not possible to determine causality, the observed kinematic differences may contribute to recurrent nature of this injury. Specifically, it is possible that neuromuscular deficits of the hip and calf muscle complex may lead to increased strain on the calf complex. Rehabilitation interventions which focus on addressing pelvis and hip kinematics may reduce the demands placed upon the calf

\footnotetext{
a Corresponding author:

Dr Christopher Bramah, PhD

Allerton Building, School of Health \& Society

University of Salford, Salford, Manchester, United Kingdom, M6 6PU.

c.a.bramah@salford.ac.uk
} 
complex and could prove clinically effective.

\section{INTRODUCTION}

Running is an increasingly popular method of physical activity; however it also poses a considerable risk of injury with an estimated one in three runners being injured in their lifetime. ${ }^{1}$ Of all running injuries, the majority are thought to occur to the knee and lower limb, accounting for 7 to $50 \%$ and 9 to $32 \%$ of all running injuries respectively. ${ }^{2}$ One lower limb injury commonly experienced by runners is calf muscle strain injury (CMSI). CMSIs can occur to either the soleus or the gastrocnemius muscles and often present as sudden onset of pain localised to the calf muscle belly, with an inability to continue activity. ${ }^{3}$ Amongst running populations, previous literature has reported prevalence rates of CMSI to range from 12 to $23.3 \% 4,5$ and incidence rates ranging between $4.5 \%$ and $33 \% .^{5-7}$ CMSIs are also known to have recurrence rates as high as $38 \%,{ }^{8}$ suggesting that underlying contributors to CMSI remain unaddressed following return to running.

Currently there are only a limited number of studies investigating factors associated with CMSIs. Of the available literature, studies have identified male gender, ${ }^{7}$ greater age, higher body mass index (BMI) and having suffered a previous $\mathrm{CMSI}^{9}$ as the main risk factors for CMSI. It is hypothesised that these risk factors may contribute to biomechanical and neuromuscular maladaptation resulting in increased vulnerability of the calf complex to further injury. ${ }^{9}$ Although this highlights at-risk populations, many of the identified risk factors are non-modifiable and consequently cannot be targeted within the rehabilitation process. Therefore, there is a need for greater understanding of modifiable risk factors for CMSIs, as this may help inform rehabilitation programs and reduce the high reoccurrence rates of CMSI amongst runners.

During the stance phase of running, the soleus acts to control both ankle dorsiflexion and knee flexion, decelerating the downward movement of the body's mass. ${ }^{10}$ At mid to late stance both the gastrocnemius and soleus then act to plantarflex the ankle, facilitating the vertical and forward propulsion of the body. ${ }^{10,11}$ During early stance, the calf muscle contracts isometrically while the muscle tendon unit elongates, ${ }^{12,13}$ with peak muscle forces reported to reach upwards of 1.9 and 6.7 times body weight for the gastrocnemius and soleus respectively. ${ }^{14}$ It is perhaps this period of time where the calf complex is most vulnerable to injury.

Muscle strain injuries are thought to occur as tissues lengthen while exposed to high external forces. ${ }^{15,16}$ For example, hamstring strain injuries have been most frequently reported to occur during late swing phase of sprinting or during kicking actions, as the hamstrings lengthen under high forces. ${ }^{17}$ With reference to the calf complex, it has been proposed that increased ankle dorsiflexion and knee flexion during stance phase could contribute to injury development; 18 with the calf exposed to elevated muscle forces whilst musculotendinous structures are in a lengthened position. ${ }^{13,14,18,19}$ However, although a feasible explanation for CMSI, there has been minimal biomechanical research to explore this mechanism.
Currently the only available evidence investigating whether biomechanics play a role in CMSIs are limited to two case reports, ${ }^{20,21}$ with only one study reporting an injury during running. ${ }^{21}$ Specifically, Orchard et $\mathrm{al}^{20}$ reported the incidence of an acute CMSI in a cricket player, while Kong et $\mathrm{al}^{21}$ reported the onset of a CMSI in a runner. Both authors reported the onset of injury to occur around the point of peak muscle lengthening during early stance, suggesting the biomechanical loads associated with high external forces as the tissues lengthen may result in elevated tissue strain and injury. ${ }^{20,21}$ Although these studies provide insight into the mechanics occurring at the moment of injury, they are limited to only one participant and therefore may not be generalisable to wider populations.

Understanding potential kinematic differences between runners with a history of repeat CMSI and injury free controls may provide information to direct future rehabilitation and preventative strategies for this injury. Therefore, the aim of this study was to investigate whether male runners with a history of repeat calf muscle strain injury demonstrate differences in stance phase running kinematics when compared to healthy controls. It was hypothesised that runners with a history of recurrent calf muscle injury would demonstrate either increased peak ankle dorsiflexion or knee flexion angles during the stance phase of running. These kinematic patterns could increase the strain placed upon the calf muscle complex which may contribute to repeat CMSI.

\section{METHODS}

A total of 30 rearfoot strike male runners were enrolled in this study, including 15 runners with a history of repeat calf muscle strain injury and 15 controls (Table 1). Participants were assessed by the lead clinician to confirm injury history and diagnosis prior to participation. All participants provided written informed consent prior to being enrolled in this study and ethical approval was obtained from the local ethics committee.

All participants were injury free at the time of testing and therefore we were unable to distinguish whether the original injuries occurred to the gastrocnemius or soleus muscle. As such, these injuries were classified more broadly as calf muscle strain injury (CMSI). Participants were included within the CMSI group providing they reported a history of two or more CMSIs within the last 12 months. A history of unilateral injuries was reported in six participants and bilateral injuries in nine participants. One participant reported their most recent CMSI to have occurred within the prior six months, 10 reported sustaining a CMSI within the prior three months, one within the prior two months and a further two participants reported experiencing their most recent injury within the prior month. Symptoms were described as a sudden onset of pain localised to the calf muscle resulting in an inability to continue running. Participants were excluded if they reported any prior injury to the lower back, previous lower limb surgery, neurological impairment or any previous traumatic injury to the lower limb. Participants were included within the control group 
Table 1: Participant characteristics, Mean (standard deviation).

\begin{tabular}{|l|l|l|l|l|}
\hline \multicolumn{1}{|c|}{ Parameter } & $\begin{array}{l}\text { Controls } \\
(\mathrm{n}=15)\end{array}$ & $\begin{array}{l}\text { CMSI } \\
(\mathrm{n}=15)\end{array}$ & P - Value & Effect Size \\
\hline Age (years) & $42.4(7.2)$ & $47.8(9.1)$ & 0.09 & 0.66 \\
\hline Height (cm) & $177.2(4.9)$ & $179.4(4.5)$ & 0.25 & 0.47 \\
\hline BMI (kg/m $\left.{ }^{2}\right)$ & $22.8(1.7)$ & $23.6(2.6)$ & 0.12 & 0.36 \\
\hline Run Frequency* (runs per week) & $4.7(2.0)$ & $3.2(0.9)$ & 0.02 & 0.97 \\
\hline Weekly Running Volume* (miles) & $30.1(14.6)$ & $19.8(7.4)$ & 0.03 & 0.89 \\
\hline
\end{tabular}

* indicates statistically significant difference.

providing they were running a minimum of $20 \mathrm{~km}$ per week over two or more days and reported no history of common overuse running related injuries over an 18-month period.

Kinematic data were collected from all participants while running on a treadmill at $3.2 \mathrm{~m} / \mathrm{s}$ wearing their own running shoes. After a five-minute warm up period, 30 seconds of kinematic data were collected using a 12 camera Qualysis Oqus (Göteborg, Sweden) system $(240 \mathrm{~Hz})$. Treadmill running has been reported to produce kinematics comparable to over-ground running and therefore can be considered representative of participants natural running gait. ${ }^{22} \mathrm{Ad}-$ ditionally, all participants reported being comfortable with treadmill running. A standardised running speed of $3.2 \mathrm{~m} /$ $\mathrm{s}$ was selected to avoid between participant variability in running kinematics due to speed, with this speed considered similar to average training paces commonly encountered by recreational runners ${ }^{23}$ and used in prior biomechanical studies. ${ }^{24,25}$

A total of nine anatomical segments were tracked following a previously published protocol. ${ }^{26,27}$ Segments included the thorax, pelvis and bilateral thigh, shank and foot segments. Further details of the markers used to track each segment and the precise definition of the anatomical coordinate systems are provided in previous publications. ${ }^{26,27}$

Raw kinematic data were low pass filtered at $10 \mathrm{~Hz}$. Intersegmental kinematics, along with the motions of the pelvis and thorax with respect to the laboratory system, were calculated using a six degrees of freedom model using the Visual 3d (C -Motion) software. Gait events were defined using a previously validated kinematic algorithm, ${ }^{28}$ in which initial contact was defined as the first peak in vertical acceleration of either the heel or metatarsal markers. Toe-off was identified as the vertical jerk peak of the $2^{\text {nd }}$ metatarsal marker. ${ }^{28}$ Gait events were used to segment each kinematic signal into a minimum of 10 consecutive gait cycles. An ensemble average for each signal was created and selected kinematic parameters derived from the ensemble average curves. This latter processing was carried out using a custom Matlab script.

Several kinematic parameters were selected for data analysis. Kinematic parameters included sagittal and frontal plane joint angles at initial contact, peak joint angles during stance, joint excursion of the ankle and knee and spatiotemporal parameters. Peak angles during stance were defined as the maximum joint angle between initial contact and toe off. Joint excursion was calculated as the range of movement from initial contact to the peak angle at mid stance. Spatiotemporal parameters included stride length, step rate, stance time, flight time as well as the horizontal distance between the heel marker and centre of mass at initial contact. Center of mass was calculated using a nine segment model comprised of bilateral feet, shank and thigh segments, as well as the pelvis, lumbar and thoracic spine. ${ }^{27} \mathrm{~A}$ recent study identified a link between a range of lower limb running injuries and kinematics of the pelvis and trunk. ${ }^{24}$ Therefore, kinematic parameters of the trunk, pelvis and lower limbs were included in the analysis. Independent $\mathrm{t}$ - tests were used to compare differences between groups and effect sizes calculated using Cohen's d. A critical alpha of .05 was set and effect sizes of $0.2,0.5$ and 0.8 were interpreted as small, medium and large respectively. ${ }^{29}$

\section{RESULTS}

When compared to the control group the previously injured group were found to have a significantly longer stance time $(p \leqslant 0.01)$ and greater distance between heel and center of mass at initial contact $(p \leqslant 0.01)$, characteristic of an overstride running gait (Table 2). No other significant differences were observed between the groups for any spatiotemporal parameters. There were several differences found at the hip and pelvis kinematics between the previously injured and control groups (Table 3). At initial contact the previously injured group landed with a significant $4.4^{\circ}$ increase in hip flexion $(p \leqslant 0.01)$ and a significant $3.7^{\circ}$ increase in anterior pelvic tilt $(\mathrm{p} \leqslant 0.01)$. At mid stance the previously injured group demonstrated a significant $2.1^{\circ}$ increase in peak contralateral pelvic drop $(p \leqslant 0.01)$ (Figure 1) and $3.1^{\circ}$ greater anterior pelvic tilt $(p=.03)$ when compared to the control group. These differences demonstrated large effect sizes ranging from 0.8 to 1.2 (Table 3). Interestingly, there were no significant differences observed in any of the kinematic parameters related to the knee or ankle ( $p>05$ ) (Figures $\underline{2}$ and $\underline{3}$ ).

\section{DISCUSSION}

The aim of the present study was to identify whether male runners with a history of recurrent calf muscle strain injuries demonstrate differences in running kinematics when compared to healthy controls. It was hypothesised that the CMSI group would demonstrate greater peak ankle dorsiflexion and knee flexion angles during the stance phase of 
Table 2: Spatiotemporal parameters, mean (standard deviation).

\begin{tabular}{|l|l|l|l|l|l|c|}
\hline \multirow{2}{*}{ Parameter } & Controls & CMSI & $\begin{array}{l}\text { P- } \\
\text { Value }\end{array}$ & $\begin{array}{l}\text { Effect } \\
\text { Size }\end{array}$ & \multicolumn{2}{|l|}{$\begin{array}{l}95 \% \text { Confidence } \\
\text { Interval }\end{array}$} \\
\cline { 3 - 7 } & & & & Lower & Upper \\
\hline Flight Time (sec) & $\begin{array}{l}0.204 \\
(0.04)\end{array}$ & $\begin{array}{l}0.181 \\
(0.05)\end{array}$ & 0.17 & 0.51 & -0.059 & 0.011 \\
\hline Stance time (sec) & $\begin{array}{l}0.523 \\
(0.03)\end{array}$ & $\begin{array}{l}0.562 \\
(0.04)\end{array}$ & $\leq 0.01$ & 1.10 & 0.014 & 0.063 \\
\hline Stride Length (meters) & $2.23(0.09)$ & $2.27(0.14)$ & 0.31 & 0.34 & -0.043 & 0.133 \\
\hline Stride Rate (Steps per minute) & $164.9(6.7)$ & $\begin{array}{l}162.3 \\
(10.3)\end{array}$ & 0.41 & 0.30 & -9.118 & 3.838 \\
\hline CoM Vertical Excursion (cm) & $9.3(1.0)$ & $9.3(1.5)$ & 0.88 & 0.05 & -0.896 & 1.040 \\
\hline $\begin{array}{l}\text { Heel to CoM distance at contact } \\
\text { (cm)* }\end{array}$ & $13.3(2.8)$ & $15.8(2.5)$ & $\leq 0.01$ & 0.94 & 0.44 & 4.38 \\
\hline
\end{tabular}

* indicates statistically significant difference. $\mathrm{CoM}=$ centre of mass.

Table 3: Kinematic characteristics mean (standard deviation).

\begin{tabular}{|c|c|c|c|c|c|c|}
\hline \multirow[t]{2}{*}{ Parameter } & \multirow[t]{2}{*}{ Controls } & \multirow[t]{2}{*}{ CMSI } & \multirow[t]{2}{*}{ P - Value } & \multirow[t]{2}{*}{ Effect Size } & \multicolumn{2}{|c|}{ 95\% Confidence Interval } \\
\hline & & & & & Lower & Upper \\
\hline \multicolumn{7}{|l|}{ Joint Angles at Initial contact } \\
\hline Pelvis anterior tilt ${ }^{*}\left({ }^{\circ}\right)$ & $6.2(3.5)$ & $9.9(3.7)$ & $\leq 0.01$ & 1.04 & 1.01 & 6.44 \\
\hline Hip Flexion* $\left(^{0}\right)$ & $21.8(3.5)$ & $26.3(3.9)$ & $\leq 0.01$ & 1.20 & 1.66 & 7.23 \\
\hline Knee flexion $\left(^{\circ}\right)$ & $6.3(5.4)$ & $5.4(5.2)$ & 0.64 & 0.17 & -4.88 & 3.06 \\
\hline Ankle dorsiflexion $\left({ }^{\circ}\right)$ & $9.6(4.5)$ & $11.3(6.6)$ & 0.42 & 0.29 & -2.53 & 5.89 \\
\hline Foot Inclination $\left(^{\circ}\right)$ & $20.4(6.0)$ & $23.8(6.8)$ & 0.16 & 0.53 & -1.42 & 8.20 \\
\hline \multicolumn{7}{|l|}{ Joint Angles at mid stance } \\
\hline Contralateral Pelvic Drop* $\left(^{0}\right)$ & $3.5(2.6)$ & $5.7(1.9)$ & $\leq 0.01$ & 0.94 & 0.45 & 3.83 \\
\hline Pelvis anterior tilt* $\left(^{\circ}\right)$ & $6.0(3.8)$ & $9.1(3.8)$ & 0.03 & 0.80 & 0.21 & 5.88 \\
\hline Hip Adduction $\left({ }^{\circ}\right)$ & $9.2(3.2)$ & $11.3(3.1)$ & 0.07 & 0.68 & -0.19 & 4.05 \\
\hline Knee flexion $\left({ }^{\circ}\right)$ & $33.0(2.8)$ & $33.4(5.1)$ & 0.81 & 0.09 & -2.72 & 3.46 \\
\hline Ankle Dorsiflexion $\left({ }^{\circ}\right)$ & $23.4(2.2)$ & $24.3(3.4)$ & 0.37 & 0.33 & -1.21 & 3.08 \\
\hline Rearfoot eversion $\left({ }^{\circ}\right)$ & $4.0(2.6)$ & $3.1(5.1)$ & 0.53 & 0.23 & -2.08 & 3.96 \\
\hline
\end{tabular}

All values are presented as degrees of movement $\left({ }^{0}\right) . *$ indicates statistically significant difference.

running. This hypothesis was based on the premise that excessive ankle dorsiflexion and knee flexion angles would increase the eccentric load placed on the calf complex, leading to tissue damage and injury. Contrary to this hypothesis, there were no differences in peak ankle or knee joint angles (Figures $\underline{2}$ and $\underline{3}$ ), however there were differences between groups for pelvis and hip kinematics as well as longer stance times. Therefore, it appears that there are stronger associations between proximal rather than distal kinematics and CMSIs.

In the present study, an increase in contralateral pelvic drop and anterior pelvic tilt were observed in runners with a history of calf muscle strain injury. Peak contralateral pelvic drop has previously been reported to be associated with multiple different running injuries, including iliotibial band syndrome, patellofemoral pain, medial tibial stress syndrome and Achilles tendinopathy, ${ }^{24}$ however this is the first study to identify similar associations amongst runners with CMSI. It is possible that this observation indicates potential deficits in the neuromuscular function of the gluteal muscles during the stance phase of gait. The gluteus medius is considered one of the primary stabilizers of the hip and pelvis in the frontal plane, while the gluteus maximus assists in control of anterior pelvic tilt. ${ }^{30}$ Delayed onset of these muscles has previously been reported to result in a loss of neuromuscular stiffness around the hip and pelvis, subsequently leading to altered kinematic patterns. ${ }^{31}$ Therefore, the observation of increased contralateral pelvic 
drop and anterior pelvic tilt in the CMSI group, could indicate neuromuscular deficits of the gluteal muscles which may have implications for calf muscle function during running.

The gluteal muscles play a key role in vertical support and propulsion during the stance phase of gait through synergy with the gastrocnemius, soleus and quadriceps. 10 Modelling studies have reported the gluteal muscles to provide up to half the total vertical support during running. ${ }^{11}$ Similarly, along with the soleus muscle, the gluteus maximus and posterior fibres of the gluteus medius play a role in the control of knee flexion velocity, ${ }^{32}$ generating a hip extension moment during early stance which accelerates the knee into extension. It is possible that deficits of the gluteal muscle group may reduce the hip muscle contribution to knee extension, vertical support and propulsion. This, in turn, could lead to an increase in muscular demand at the calf muscle complex and subsequent tissue overload and injury. ${ }^{33}$ If such a mechanism does play a role in the aetiology of CMSI, then rehabilitation approaches may need to focus on correcting proximal dysfunctions in order to reduce the mechanical demand on the calf muscle complex during running. However, EMG studies are now required to investigate this idea further.

The CMSI group were also observed to land with significantly greater hip flexion and distance between the heel and center of mass at initial contact, characteristic of an overstride running gait. ${ }^{34,35}$ This may explain the longer stance times observed amongst the CMSI group and could have implications for calf muscle function. In a previous study by Napier et al, ${ }^{35}$ hip flexion and heel to center of mass distance at initial contact were correlated with peak horizontal breaking force, which will slow the forward momentum of the centre of mass during early stance. Additionally, without compensatory knee and ankle kinematics, an overstride running gait will result in a posterior shift in the centre of pressure under the foot ${ }^{36}$ which may reduce the capacity for storage of elastic energy within the calf complex. Consequently, in order to reaccelerate the centre of mass at toe off, there may be a need to increase ankle power generation from mid to late stance. ${ }^{10,11}$ It is conceivable that such biomechanical compensation could increase the demand on the calf complex and may subsequently lead to repeated muscle overload and greater musculotendinous strains, increasing the risk of tissue failure and injury.

It is also possible that neuromuscular deficits of the calf complex may underlie the observation of an increase in stance time and that such deficits may place the calf complex at risk of injury. During the early stance phase of running, the calf muscle complex contracts isometrically, while the muscle tendon unit elongates. ${ }^{12,13}$ This interaction, between isometric muscle contraction and elongation of the elastic components of the muscle tendon unit, acts to store elastic energy which is later returned during the propulsion phase, accelerating the body's mass vertically. ${ }^{12,13,37-39}$ Neuromuscular deficits of the calf complex, such as reduced rate of force development, reduced peak muscle force or delayed neuromuscular activity, could subsequently reduce the ability of the muscle fascicles to remain isometric. ${ }^{26,28,40,41}$ Consequently, this may result in muscle tissue lengthening, longer stance times and an increased risk of

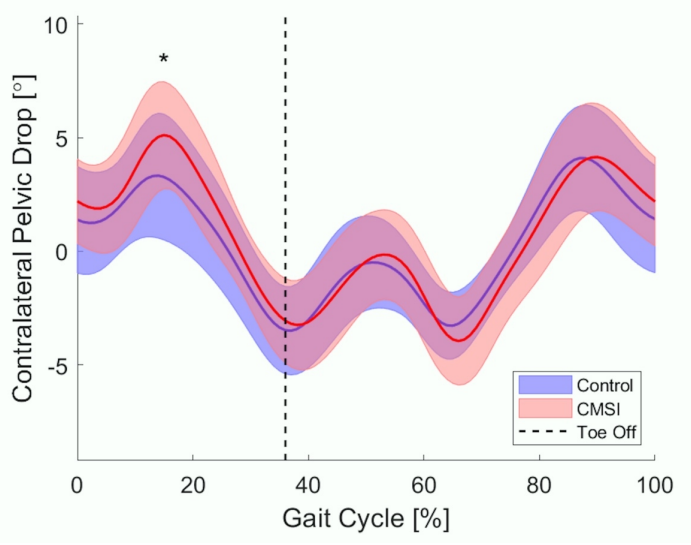

Figure 1: Frontal plane pelvis ensemble average kinematic waveform across the gait cycle.

Positive $y$-axis values represent the contralateral side of the pelvis dropping away from the side of the standing leg, negative represent the contralateral side of the pelvis elevating relative to the side of the standing leg. CMSI= calf muscle strain injury.

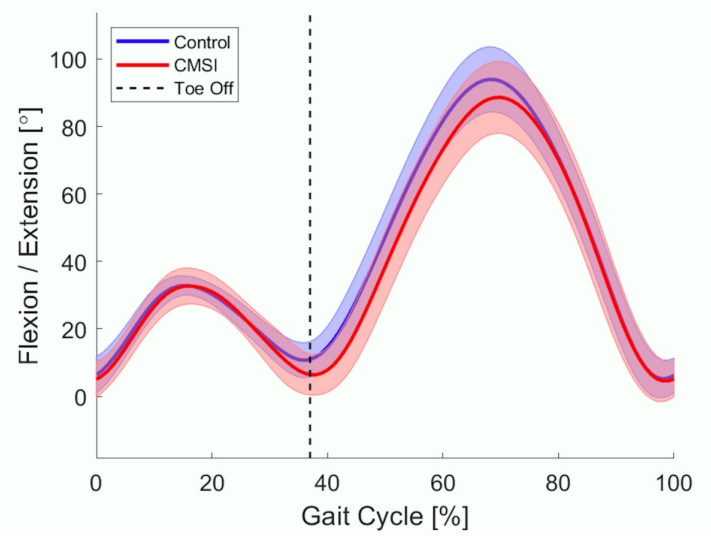

Figure 2: Sagittal plane knee ensemble average kinematic waveform across the gait cycle.

Positive $y$-axis values represent flexion, negative represent extension. CMSI= calf muscle strain injury.

muscle strain injury. ${ }^{28,42}$ Therefore it is recommend that future studies undertake more detailed investigations of muscle strength and structural properties of the calf complex in people with CMSI and also investigate whether such features underlie the observed kinematic differences between the previously injured and health groups.

The results from this current study highlight an association between specific kinematic characteristics and a history of CMSI. Although it is not possible to infer causation from these data, the study provides new insight into potential mechanisms for recurrent CMSIs. Therefore, these findings could be used to inform future research and rehabilitation strategies. Firstly, considering the finding of altered kinematics at the hip and pelvis, rehabilitation interventions focusing on hip muscle function may serve to increase proximal contributions to vertical support and propulsion during running, reducing the work required of the ankle plantarflexors. Second, gait retraining interventions may be 
a useful intervention, targeting many of the observed kinematic deficits. Specifically, increasing step rate has been shown to improve kinematics at the hip and pelvis, ${ }^{43}$ reduce over-stride, ${ }^{44}$ increase gluteal and calf muscle activation prior to foot contact ${ }^{45}$ and reduce force requirements at the ankle joint. ${ }^{46}$ Therefore, gait retraining may prove beneficial in the management of runners with recurrent CMSI through the restoration of mechanical deficits. Finally, future studies should consider formalised assessment of muscle activation patterns and plantarflexor muscle strength, as deficits in peak muscle force or rate of force development can be addressed within the rehabilitation process and could play a role in the recurrent nature of this injury.

There are some limitations which must be acknowledged. Due to the retrospective nature of this study it cannot be confirmed whether the observed kinematics are the cause or effect of injury. The CMSI group did demonstrate a significantly lower weekly training volume and running frequency when compared to the control group (Table 1). Therefore, it is possible that repeated interruption to training exposure due to injury, could have a negative impact on both tissue and biomechanical function. ${ }^{36,47,48}$ However, considering the recurrent nature of CMSIs, it is possible that the observed kinematics represent ongoing neuromuscular and functional deficits which may contribute to the persistence of this injury.

An additional limitation is that all participants were required to run at the same testing speed of $3.2 \mathrm{~m} / \mathrm{s}$. Consequently, some participants may have been running at a speed slightly faster or slower than preferred. However, a prior publication investigating biomechanical differences between high-performance and recreational runners across a range of testing speeds, ${ }^{36}$ suggested between-group biomechanical differences may occur irrespective of testing speed. Therefore, subtle variations in running speed are unlikely to have influenced the between group kinematic findings of the present study. Finally, the current study was restricted to a male population of rearfoot strikers. Therefore, further work is required to understand if the observed kinematic patterns are characteristic of other populations, such as forefoot strikers and female runners.

\section{CONCLUSION}

This study is the first to identify that male runners with a history of recurrent calf muscle strain injury demonstrate altered stance phase running kinematics. In contrast to the original hypothesis, the data suggest a strong link between

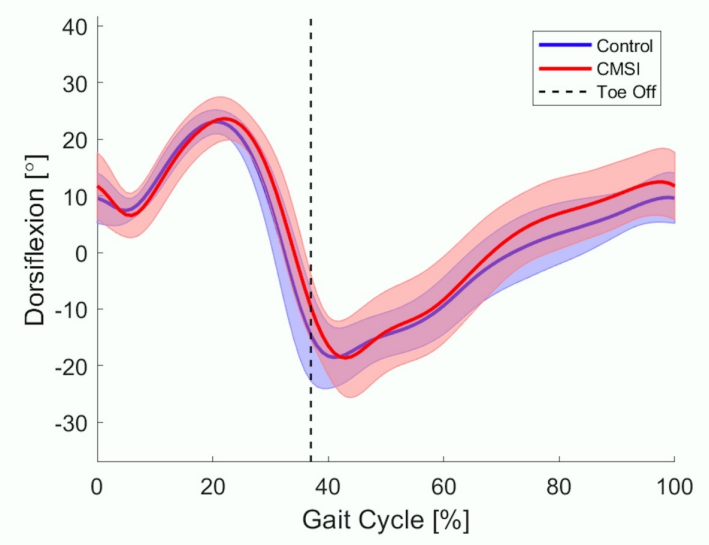

Figure 3: Sagittal plane ankle ensemble average kinematic waveform across the gait cycle.

Positive y-axis values represent dorsiflexion, negative represent plantarflexion. CMSI $=$ calf muscle strain injury.

pelvic-hip kinematics and the presence of CMSI injury. These findings may be the result of underlying neuromuscular deficits which are consistent with the recurrent nature of this injury. Based on these findings further research should consider assessment of muscle activation patterns as well as the force generating capacity of the calf and hip complex, as this may explain the observed kinematic patterns and can be targeted within the rehabilitation process. Gait retraining interventions may also prove useful as a short-term intervention, addressing the observed proximal kinematic deficits which may have positive implications for the function of the calf complex.

\section{ACKNOWLEDGEMENTS}

No external financial support was received for this study.

\section{CONFLICT OF INTEREST}

The authors report no conflicts of interest.

Submitted: August 15, 2020 CDT, Accepted: January 07, 2021

CDT 


\section{REFERENCES}

1. Taunton JE, Ryan MB, Clement DB, McKenzie DC, Lloyd-Smith DR, Zumbo BD. A retrospective casecontrol analysis of 2002 running injuries. Br J Sports Med. 2002;36(2):95-101.

2. van Gent RN, Siem D, van Middelkoop M, et al. Incidence and determinants of lower extremity running injuries in long distance runners: a systematic review. Br J Sports Med. 2007;41(8):469-480. doi:10.1136/bjsm.2006.033548

3. Brukner P, Khan K. Clinical Sports Medicine. 3rd ed. Australia: McGraw-Hill Australia Pty Ltd; 2009.

4. Vitez L, Zupet P, Zadnik V, Drobnič M. Running Injuries in the participants of Ljubljana marathon. Zdr Varst. 2017;56(4):196-202. doi:10.1515/sjph-201 $\underline{7-0027}$

5. Van Middelkoop M, Kolkman J, Van Ochten J, Bierma-Zeinstra SM, Koes B. Prevalence and incidence of lower extremity injuries in male marathon runners. Scand J Med Sci Sports. 2008;18(2):140-144. doi:10.1111/j.1600-0838.2007.00 683.x

6. Lopes AD, Hespanhol Junior LC, Yeung SS, Costa LO. What are the main running-related musculoskeletal injuries? A Systematic Review. Sports Med. 2012;42(10):891-905. doi:10.2165/11631170-000 000000-00000

7. Satterthwaite P, Norton R, Larmer P, Robinson E. Risk factors for injuries and other health problems sustained in a marathon. Br J Sports Med. 1999;33(1):22-26. doi:10.1136/bjsm.33.1.22

8. Rauh MJ, Margherita AJ, Rice SG, Koepsell TD, Rivara FP. High school cross country running injuries: a longitudinal study. Clin J Sport Med. 2000;10(2):110-116.

9. Green B, Pizzari T. Calf muscle strain injuries in sport: a systematic review of risk factors for injury. $\mathrm{Br}$ J Sports Med. 2017;51(16):1189-1194. doi:10.1136/bjs ports-2016-097177

10. Sasaki K, Neptune RR. Differences in muscle function during walking and running at the same speed. J Biomech. 2006;39(11):2005-2013. doi:10.101 6/i.jbiomech.2005.06.019

11. Hamner SR, Seth A, Delp SL. Muscle contributions to propulsion and support during running. J Biomech . 2010;43(14):2709-2716. doi:10.1016/j.jbiomech.201 0.06 .025
12. Lai A, Lichtwark GA, Schache AG, Lin YC, Brown NA, Pandy MG. In vivo behavior of the human soleus muscle with increasing walking and running speeds. $J$ Appl Physiol. 2015;118(10):1266-1275. doi:10.1152/ja pplphysiol.00128.2015

13. Lai AKM, Lichtwark GA, Schache AG, Pandy MG. Differences in in vivo muscle fascicle and tendinous tissue behavior between the ankle plantarflexors during running. Scand J Med Sci Sports. 2018;28(7):1828-1836. doi:10.1111/sms.13089

14. Dorn TW, Schache AG, Pandy MG. Muscular strategy shift in human running: dependence of running speed on hip and ankle muscle performance. J Exp Biol. 2012;215(11):1944-1956. doi:10.1242/jeb.0 $\underline{64527}$

15. Balius R, Alomar X, Rodas G, et al. The soleus muscle: MRI, anatomic and histologic findings in cadavers with clinical correlation of strain injury distribution. Skeletal Radiol. 2013;42(4):521-530. do $\mathrm{i}: 10.1007 / \mathrm{s} 00256-012-1513-3$

16. Maffulli N, Del Buono A, Oliva F, et al. Muscle Injuries: A Brief Guide to Classification and Management. Transl Med UniSa. 2015;12:14-18.

17. Danielsson A, Horvath A, Senorski C, et al. The mechanism of hamstring injuries - a systematic review. BMC Musculoskeletal Disorders. 2020;21(1):641. doi:10.1186/s12891-020-03658-8

18. Fields KB, Rigby MD. Muscular Calf Injuries in Runners. Curr Sports Med Rep. 2016;15(5):320-324. do i:10.1249/jsr.0000000000000292

19. Lichtwark GA, Wilson AM. Optimal muscle fascicle length and tendon stiffness for maximising gastrocnemius efficiency during human walking and running. J Theor Biol. 2008;252(4):662-673. doi:10.10 16/j.jtbi.2008.01.018

20. Orchard JW, Alcott E, James T, Farhart P, Portus $\mathrm{M}$, Waugh SR. Exact moment of a gastrocnemius muscle strain captured on video. Br J Sports Med. 2002;36(3):222-223. doi:10.1136/bjsm.36.3.222

21. Kong PW. Gastrocnemius injury during running: a case report. Int J Sports Med. 2009;30(1):46-52.

22. Van Hooren B, Fuller JT, Buckley JD, et al. Is motorized treadmill running biomechanically comparable to overground running? A Systematic Review and Meta-Analysis of Cross-Over Studies. Sports Med. 2020;50(4):785-813. doi:10.1007/s4027 9-019-01237-z 
23. Fokkema T, van Damme A, Fornerod MWJ, de Vos RJ, Bierma-Zeinstra SMA, van Middelkoop M. Training for a (half-)marathon: Training volume and longest endurance run related to performance and running injuries. Scand J Med Sci Sports. 2020;30(9):1692-1704. doi:10.1111/sms.13725

24. Bramah C, Preece SJ, Gill N, Herrington L. Is There a pathological gait associated with common soft tissue running injuries? Am J Sports Med. 2018;46(12):3023-3031. doi:10.1177/03635465187936 $\underline{57}$

25. Noehren B, Pohl MB, Sanchez Z, Cunningham T, Lattermann C. Proximal and distal kinematics in female runners with patellofemoral pain. Clin Biomech. 2012;27(4):366-371. doi:10.1016/j.clinbiome ch.2011.10.005

26. Mason DL, Preece SJ, Bramah CA, Herrington LC. Reproducibility of kinematic measures of the thoracic spine, lumbar spine and pelvis during fast running. Gait Posture. 2016;43:96-100. doi:10.1016/j.gaitpost.2 013.11.007

27. Preece SJ, Mason D, Bramah C. The coordinated movement of the spine and pelvis during running. Hum Mov Sci. 2016;45:110-118. doi:10.1016/i.humo v.2015.11.014

28. Handsaker JC, Forrester SE, Folland JP, Black MI, Allen SJ. A kinematic algorithm to identify gait events during running at different speeds and with different footstrike types. J Biomech. 2016;49(16):4128-4133. d oi:10.1016/j.jbiomech.2016.10.013

29. Cohen J. In: Statistical Power Analysis for the Behavioral Sciences. Revised Edition. Academic Press; 1977:iv.

30. Neumann DA. Kinesiology of the hip: a focus on muscular actions. J Orthop Sports Phys Ther. 2010;40(2):82-94. doi:10.2519/jospt.2010.3025

31. Willson JD, Kernozek TW, Arndt RL, Reznichek DA, Scott Straker J. Gluteal muscle activation during running in females with and without patellofemoral pain syndrome. Clin Biomech. 2011;26(7):735-740.

32. Arnold AS, Anderson FC, Pandy MG, Delp SL. Muscular contributions to hip and knee extension during the single limb stance phase of normal gait: a framework for investigating the causes of crouch gait. J Biomech. 2005;38(11):2181-2189. doi:10.1016/i.jbio mech.2004.09.036

33. Winter DA. Overall principle of lower limb support during stance phase of gait. J Biomech. 1980;13(11):923-927.
34. Lieberman DE, Warrener AG, Wang J, Castillo ER. Effects of stride frequency and foot position at landing on braking force, hip torque, impact peak force and the metabolic cost of running in humans. $J$ Exp Biol. 2015;218(Pt 21):3406-3414. doi:10.1242/je b. 125500

35. Napier C, MacLean CL, Maurer J, Taunton JE, Hunt MA. Kinematic correlates of kinetic outcomes associated with running-related injury. $J \mathrm{Appl}$ Biomech. 2019;35(2):123-130. doi:10.1123/jab.2018-0 $\underline{203}$

36. Preece SJ, Bramah C, Mason D. The biomechanical characteristics of high-performance endurance running. Eur J Sport Sci. 2019;19(6):784-792. doi:10.1 $\underline{080 / 17461391.2018 .1554707}$

37. Lichtwark GA, Bougoulias K, Wilson AM. Muscle fascicle and series elastic element length changes along the length of the human gastrocnemius during walking and running. J Biomech. 2007;40(1):157-164. doi:10.1016/i.jbiomech.2005.10.035

38. Ishikawa M, Niemela E, Komi PV. Interaction between fascicle and tendinous tissues in shortcontact stretch-shortening cycle exercise with varying eccentric intensities. J Appl Physiol. 2005;99(1):217-223. doi:10.1152/japplphysiol.01352.2 $\underline{004}$

39. Ishikawa M, Komi PV. Effects of different dropping intensities on fascicle and tendinous tissue behavior during stretch-shortening cycle exercise. J Appl Physiol. 2004;96(3):848-852. doi:10.1152/japplphysio $\underline{1.00948 .2003}$

40. Hamner SR, Delp SL. Muscle contributions to fore-aft and vertical body mass center accelerations over a range of running speeds. J Biomech. 2013;46(4):780-787. doi:10.1016/i.jbiomech.2012.11.0 $\underline{24}$

41. Gollhofer A, Kyröläinen H. Neuromuscular control of the human leg extensor muscles in jump exercises under various stretch-load conditions. Int J Sports Med. 1991;12(1):34-40. doi:10.1055/s-2007-1024652

42. Van Hooren B, Bosch F. Is there really an eccentric action of the hamstrings during the swing phase of high-speed running? part I: A critical review of the literature. J Sports Sci. 2017;35(23):2313-2321. doi:1 $0.1080 / 02640414.2016 .1266018$

43. Bramah C, Preece SJ, Gill N, Herrington L. A 10\% Increase in step rate improves running kinematics and clinical outcomes in runners with Patellofemoral pain at 4 Weeks and 3 months. Am J Sports Med. 2019;47(14):3406-3413. doi:10.1177/03635465198796 $\underline{93}$ 
44. Heiderscheit BC, Chumanov ES, Michalski MP, Wille CM, Ryan MB. Effects of step rate manipulation on joint mechanics during running. Med Sci Sports Exerc. 2011;43(2):296-302. doi:10.1249/MSS.0b013e3 181ebedf4

45. Chumanov ES, Wille CM, Michalski MP, Heiderscheit BC. Changes in muscle activation patterns when running step rate is increased. Gait Posture. 2012;36(2):231-235. doi:10.1016/j.gaitpost.2 $\underline{012.02 .023}$

46. Lyght M, Nockerts M, Kernozek TW, Ragan R. Effects of foot strike and step frequency on Achilles tendon stress during running. J Appl Biomech. 2016;32(4):365-372. doi:10.1123/jab.2015-0183
47. Paquette MR, Powell DW, DeVita P. Age and training volume influence joint kinetics during running. Scand J Med Sci Sports. 2020. doi:10.1111/sm $\underline{\text { s. } 13857}$

48. Paquette MR, Devita P, Williams, D. S. B., 3rd. Biomechanical Implications of Training Volume and Intensity in Aging Runners. Med Sci Sports Exerc. 2018;50(3):510-515. doi:10.1249/mss.0000000000001 $\underline{452}$ 